\section{Patterns of prescribing hydroxyurea for sickle cell disease patients from a central hospital, Saudi Arabia}

\author{
Assem A. Elghazaly, Adel A. Aljatham, \\ Abdulaziz M. Khan, Rasha M. Elneil, \\ S. Zubair S. Jafar, Salah A. Elwishy, \\ Omsalma E. Ahmed, Aamer M. \\ Bughnah, Mamoun H. Ibrahim \\ Department of Adult Hematology \\ Oncology, King Saud Medical City, \\ Riyadh, Saudi Arabia
}

\begin{abstract}
Sickle cell disease (SCD) is a group of inherited disorders of hemoglobin synthesis. It is prevalent in different parts of the world, including the Kingdom of Saudi Arabia. The disease is associated with multiple acute and chronic life-threatening complications. Hydroxyurea (HU) is an effective preventive medication; its use has resulted in decreased morbidity and mortality. However, practice variability, including underutilization of HU, has been reported. No local publication has addressed this issue. The aim of this work is to consider the pattern of HU prescription for SCD patients. This is a retrospective study included patients seen in the outpatient clinics in a central hospital. Cases of medications unavailability or patient refusal to take the drug were not included. A total of 152 patients were included, of them 118 were prescribed HU and 34 were not. In 133 $(87.5 \%)$ patients, the physician's decision was appropriate. Inappropriate decisions including both under prescription and, to much lesser extent, over utilization had been demonstrated in $19(12.5 \%)$ cases. Impact of raising the healthcare providers' awareness and improving compliance with the updated SCD management recommendations and guidelines deserve further studying. In our local experience, although the majority of HU prescriptions were appropriate, both under prescription and to a lesser extent, overutilization was demonstrated.
\end{abstract}

\section{Introduction}

Sickle cell disease (SCD) is a group of inherited conditions of hemoglobin formation. It is associated with many acute and chronic complications that cause significant morbidity and mortality. ${ }^{1}$ The disease's prevalence in Africa is in the range of 1-2\% in the north, while it is less than $1 \%$ in the south. In the United States, SCD affects around 72,000 people, while in the United Kingdom; 12,500-15,000 people have the disease. $^{2}$ In the Kingdom of Saudi Arabia (KSA) with a population of 20.4 million, the reported overall prevalence of the genotype SS (commonest genotype) is $1.06 \%$ with a trait of $7.3 \%{ }^{3,4}$

Hydroxyurea (HU) is the first approved SCD modifying agent. It reduces the frequency of vaso-occlusive crises (VOCs), mortality, acute chest syndrome (ACS), blood transfusions, admission, length of stay, and opioid utilization during hospitalization. ${ }^{5-8}$ For SCD patients, the recommended indications for HU include the following: adults with three or more severe VOCs during any 12-month period, SCD pain or chronic anemia interfering with daily activities, severe or recurrent episodes of ACS and cerebrovascular stroke (CVS) with lack of possibility to implement a transfusion program. ${ }^{9}$

Practice variability in prescribing $\mathrm{HU}$ and underutilization, both have been reported from different parts of the world. ${ }^{9,10}$ No local study has addressed this issue before. The aim of this work is to study the pattern of prescribing HU from a central hospital in KSA.

\section{Materials and Methods}

This is a medical record-based retrospective study of 152 patients. The study covered SCD patients seen in the outpatient clinics at King Saud Medical City, Riyadh KSA, from May 2017 to January 2018. The inclusion criteria are: SCD patients at or above the age of 14 years, whether or not receiving HU. Cases with medication unavailability or patient refusal to receive the drug were not included. The study was approved by the Hospital Institutional Review Board.

\section{Results}

The basic characteristics of the patients are shown in Table 1. A total of 152 patients were included, 78 males and 74 females, with an age range of 14-40 years. HU was prescribed in 118 patients, while it was not prescribed in 34.

Regarding the patients for whom HU
Correspondence: Assem A. Elghazaly, Department of Adult Hematology Oncology, King Saud Medical City, AlShemisy Area, PO Box 366254, Riyadh 11393, Saudi Arabia.

E-mail: aymanusam@hotmail.com

Key words: SCD; HU; Over- and under prescription.

Contributions: the authors contributed equally

Conflict of interest: the authors declare no potential conflict of interest.

Funding: none.

Received for publication: 3 September 2018. Accepted for publication: 7 December 2018.

This work is licensed under a Creative Commons Attribution-NonCommercial 4.0 International License (CC BY-NC 4.0).

CCopyright A.A. Elghazalyet al., 2019

Licensee PAGEPress, Italy

Hematology Reports 2019; 11:7860

doi:10.4081/hr.2019.7860

was prescribed $(n=118)$, in $106(90 \%)$ of them, there was at least one appropriate indication for prescribing the medication. VOC requiring hospital admission was the reason for $\mathrm{HU}$ prescription in 58 of these patients, with a range of 3-10 episodes per year. ACS was the indication in 12 patients, with a range of 1-3 episodes.

Other indications include anemia or painful episodes interfering with daily activity or patients with history of stroke who were not on regular exchange transfusion; these were evident in 4, 2, and 3 patients, respectively. Twenty-six patients had two indications; these were VOC and ACS, VOC and anemia interfering with daily activity, VOC and CVS, and ACS and CVS, which were present in $18,4,1$, and 3 patients, respectively. One patient had VOC, ACS, and stroke.

In $12(10 \%)$ patients in whom the HU was prescribed, none of the recommended indications were present (over utilized/inappropriate prescription; Table 2).

Considering the patients for whom medication was not prescribed $(n=34)$, in 27 $(79 \%)$ patients, there was no indication (appropriate decision), while in 7 (21\%) cases, it was underutilized (inappropriate; Table 2). For the patients for whom the HU was underutilized, frequent admissions for VOC (3-4 episodes per year), one episode of ACS, and a history of CVS (not on regular exchange transfusion) were present in 4, 2 , and 1 patient(s), respectively. 
Table 1. Basic patients' characteristics.

\begin{tabular}{|c|c|c|}
\hline \multirow[t]{2}{*}{ Characteristic (n=152) } & \multicolumn{2}{|c|}{ HU prescription } \\
\hline & Prescribed $(n=118)$ & Not prescribed ( $n=34)$ \\
\hline Age range (years) & $14-40$ & $14-37$ \\
\hline Male: female & $63: 55$ & $15: 19$ \\
\hline Three or more admissions per year for VOC & 58 & 4 \\
\hline History of acute chest syndrome* & 12 & 2 \\
\hline Anemia interfering with daily activity. & 4 & 0 \\
\hline Stroke, not on regular exchange transfusion & 3 & 1 \\
\hline Painful episodes interfering with daily activity** & 2 & 0 \\
\hline $\begin{array}{l}\text { VOC and ACS } \\
\text { VOC and anemia*** } \\
\text { VOC and CVS } \\
\text { ACS and CVS } \\
\text { VOC, ACS, and CVS }\end{array}$ & $\begin{array}{l}18 \\
4 \\
1 \\
3 \\
1\end{array}$ & \\
\hline No indication & 12 & 27 \\
\hline
\end{tabular}

HU hydroxyurea; VOC vaso-occlusive crisis; ACS acute chest syndrome; CVS cerebrovascular stroke. *Either severe or recurrent. ** Other than moderate/severe or severe VOC. ***Interfering with daily activity.

Table 2. Pattern of HU prescription.

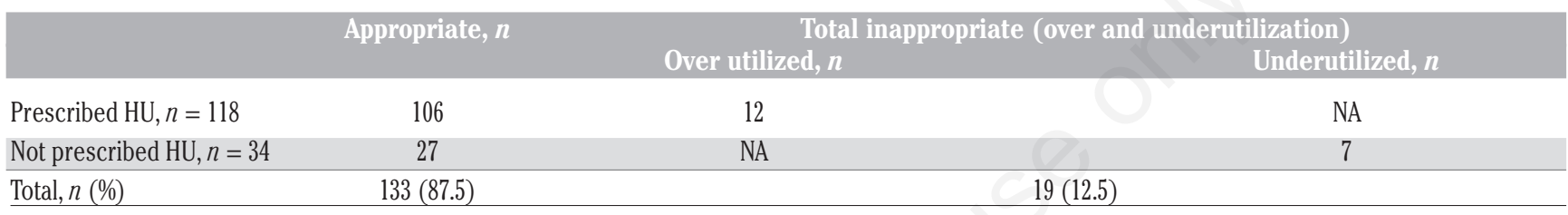

HU hydroxyurea. NA not applicable.

\section{Discussion}

HU constitutes a disease modifying agent for SCD with multiple advantages, including decreased morbidity and mortality. Our study has demonstrated variability in the prescription practice. Understanding such variability is needed for better adherence to the SCD treatment recommendations and guidelines.

Underutilization had been reported in more than one study. ${ }^{12-15}$ Among the contributing factors are lacking of awareness and poor compliance of the healthcare providers with the treatment guidelines and updates, their concern about patients' fertility and the theoretical carcinogenic potential on HU. ${ }^{11,14,15}$ Variability in practice between the different healthcare levels (community vs. university) has also been reported..$^{10}$ In this study cases with medication unavailability or patient refusal to receive it, were not included.

In our study, most prescriptions were appropriate. However, both underutilization and much less frequent overprescribing practice were demonstrated (Table 2). To our knowledge, over prescription has not been previously reported.

The current study has shown the commonest indication was the VOC followed by ACS. These results are consistent with previous publications. ${ }^{10,12}$ In contrast prescribing HU for the two more recently recommended indications, chronic anemia and frequent painful episodes that interfere with daily activities, is rare. ${ }^{9}$

A limitation of this study is including patients only from a central hospital, whereas primary health care and other more advanced centers might have different patient characteristics and physicians' practice.

\section{Conclusions}

In conclusion, in our study, although the majority of $\mathrm{HU}$ prescription practice is appropriate, both under prescription, and to a lesser extent, overutilization was demonstrated. The impact of raising the healthcare providers' awareness and improving compliance with the updated SCD management guidelines deserves further studying.

\section{References}

1. National Institute for Health and Clinical Excellence (NICE). Management of an acute painful sickle cell episode in hospital. 2012. Available from: https://www.nice.org.uk/guid- ance $/ \operatorname{cg} 143$

2. World Health Organization, Genomic Resource Centre. Genes and human disease, monogenic diseases: Sickle cell disease. Victor Boulyjenkov. Available from: http://www.who.int/genemics /genetic diseases (accessed on May 22, 2018).

3. El Hazmi MA, Warsy AS, al-Swailem AR, et al. Sickle cell gene in the population of Saudi Arabia. Hemoglobin 1996;20:187-98.

4. Abdulaali MK. Sickle cell disease patients in eastern province of Saudi Arabia suffer less severe acute chest syndrome than patients with African haplotypes. Ann Thorac Med 2007;2: 158-62.

5. Charache S, Terrin ML, Moore RD, et al. Effect of hydroxyurea on the frequency of painful crises in sickle cell anemia. N Engl J Med 1995;332:131722.

6. Steinberg MH, Barton F, Castro O, et al. Effect of hydroxyurea on mortality and morbidity in adult sickle cell anemia: risks and benefits up to 9 years of treatment. JAMA 2003;289:1645-51.

7. Ballas SK, Bauserman RL, McCarthy WF, et al. Hydroxyurea and acute painful crises in sickle cell anemia: effects on hospital length of stay and opioid utilization during hospitaliza- 
tion, outpatient acute care contacts, and at home. J Pain Symptom Manag 2010;40:870-82.

8. FDA. FDA approves hydroxyurea for treatment of pediatric patients with sickle cell. FDA 2017. Available from: https://www.fda.gov/Drugs/Information OnDrugs/ApprovedDrugs/ucm590096. htm

9. Yawn BP, Buchanan GR, Afenyi-Annan $\mathrm{AN}$, et al. Management of sickle cell disease, 2014 evidence-based report by expert panel members. JAMA 2014;312:1033-48.

10. Brandow AM, Jirovec DL, Panepinto JA. Hydroxyurea in children with sickle cell disease: practice patterns and barri- ers to utilization. Am J Hematol 2010;85:611-3.

11. Oghuvwu OS, Adewoyin AS. Hydroxyurea therapy in adult Nigerian sickle cell disease: a monocentric pilot survey on pattern of use, clinical effects and patient's compliance. ATS Journal, ajrccm-conference.2016.193.1. Meeting Abstracts. A5159.

12. Creary S, Zickmund S, Ross D, et al. Hydroxyurea therapy for children with sickle cell disease: describing how caregivers make this decision. BMC Res Notes 2015;8:372.

13. Zumberg MS, Reddy S, Boyette RL, et al. Hydroxyurea therapy for sickle cell disease in community-based practices: a survey of Florida and North Carolina hematologists/oncologists. Am J Hematol 2005;79:107-13.

14. Lanzkron S, Haywood C Jr, Hassell KL, et al. Provider barriers to hydroxyurea use in adults with sickle cell disease: a survey of the Sickle Cell Disease Adult Provider Network. J Natl Med Assoc 2008;100:968-73.

15. Brandow AM, Panepinto JA. Hydroxyurea use in sickle cell disease: the battle with low rates of prescription, poor patient compliance, and fears of toxicities and side effects. Exp Rev Hematol 2010;3:255-60. 